\title{
Living Cationic Polymerization of a Vinyl Ether with a Malonic Ester Function
}

\author{
Dedicated to the Memory of the late Professor Ichiro Sakurada
}

\author{
Toshinobu Higashimura, Takashi EnOKI, and Mitsuo SAWAMOTO
}

Department of Polymer Chemistry, Faculty of Engineering, Kyoto University, Kyoto 606, Japan

(Received January 23, 1987)

\begin{abstract}
Cationic polymerization of diethyl (2-(vinyloxy)ethyl)malonate [1; $\mathrm{CH}_{2}=\mathrm{CH}-$ $\left.\mathrm{OCH}_{2} \mathrm{CH}_{2} \mathrm{CH}\left(\mathrm{COOC}_{2} \mathrm{H}_{5}\right)_{2}\right]$, initiated by the hydrogen iodide/iodine $\left(\mathrm{HI} / \mathrm{I}_{2}\right)$ system in toluene at $-40^{\circ} \mathrm{C}$, led to living polymers consisting of a poly(vinyl ether) backbone and malonic ester pendants. The polymers possessed a very narrow molecular weight distribution $\left(\bar{M}_{w} / \bar{M}_{n} \leq 1.1\right)$, and their molecular weight $\left(\bar{M}_{n}\right)$ increased proportionally to monomer conversion or upon addition of a fresh feed of the monomer to a completely polymerized reaction mixture. Polymers of 1 with a fairly high molecular weight $\left(\bar{M}_{w}=6 \times 10^{4}\right)$ and a broad molecular weight distribution $\left(\bar{M}_{w} / \bar{M}_{n}>2\right)$ were obtained with boron trifluoride etherate as initiator otherwise under the same conditions. Saponification of the malonate polymers, followed by neutralization, yielded the corresponding diacid form (3), which underwent decarboxylation on heating in water to give the monocarboxylic acid form (4).

KEY WORDS Diethyl (2-(Vinyloxy)ethyl)malonate / Vinyl Ether / Hydrogen Iodide / Iodine / Living Polymerization / Cationic Polymerization / Polymeric Carboxylic Acid / Polyelectrolyte / Monodisperse Polymer /
\end{abstract}

We have been interested in the synthesis of functional polymers based on living cationic polymerization of vinyl ethers $\left(\mathrm{CH}_{2}=\mathrm{CH}-\right.$ $\mathrm{OCH}_{2} \mathrm{CH}_{2}-\mathrm{R}$ ) that possess pendant functional groups including esters ( $\mathrm{R}=\mathrm{OCOCH}_{3}$, etc) and poly(oxyethylene) chains $[\mathrm{R}=$ $\left.\mathrm{O}\left(\mathrm{CH}_{2} \mathrm{CH}_{2} \mathrm{O}\right)_{n} \mathrm{C}_{2} \mathrm{H}_{5}\right]{ }^{1} \quad$ Although such polar functions are known to cause side reactions in the Lewis-acid-initiated cationic polymerization, these "functionalized" vinyl ethers led to well-defined living polymers ${ }^{1 b}$ when polymerized by the hydrogen iodide/ iodine $\left(\mathrm{HI} / \mathrm{I}_{2}\right)$ initiating system. ${ }^{2}$ It occurred to us that the use of 2-chloroethyl vinyl ether $(\mathrm{R}=\mathrm{Cl})$ as an alkyl halide in the malonic ester synthesis (eq 1) would give diethyl (2-(vinyloxy)ethyl)malonate (1), a new functionalized vinyl ether carrying a malonic ester in the pendant. The malonate vinyl ether 1 has already been prepared by organic chemists, ${ }^{3}$ but its cationic polymerization remains unknown thus far.

If the double ester function of $\mathbf{1}$ does not exert adverse effects, cationic polymerization of the malonate vinyl ether will produce polymer 2, the malonate pendants of which may serve as functional groups in its subsequent chemical modification. ${ }^{4}$ Also, alkaline hydrolysis of the malonate moiety of $\mathbf{2}$, followed by thermal decarboxylation, will lead to polymeric carboxylic acid 4 via the corresponding diacid form 3 (eq 1). We recently applied a similar strategy to the synthesis of end-functionalized poly(vinyl ethers) capped with malonate or carboxylic acid groups. ${ }^{5}$

As an ester-containing vinyl ether, 1 differs from 5 (2-(vinyloxy)ethyl acetate), another 


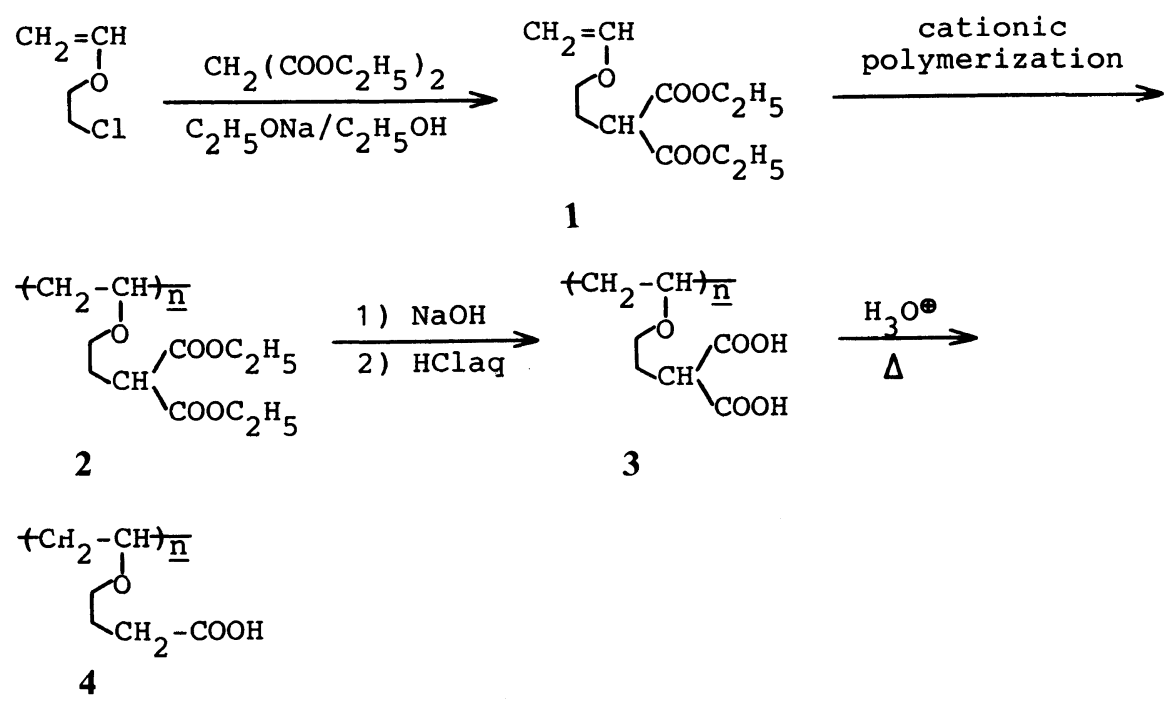

functionalized monomer previously studied by us. ${ }^{6}$ The vinyl ether moiety of $\mathbf{1}$ is connected, via a spacer, to the carbonyl carbons of the malonate pendant, whereas 5 carries its vinyl group on the ether oxygen of the acetate.<smiles>C=COCCC(C(=O)CC)C(=O)C(CCOC=C)C(=O)OCC</smiles>

\section{5}

Upon hydrolysis, therefore, polymers of 1 yield polycarboxylic acids (3 and 4); those of 5 produce polyalcohols $\mathrm{HCH}_{2}-\mathrm{CH}$ $\left.\left(\mathrm{OCH}_{2} \mathrm{CH}_{2} \mathrm{OH}\right)\right]_{n} .{ }^{6}$ Thus, among our functionalized vinyl ethers, ${ }^{1 \mathrm{~b}} \mathbf{1}$ is the first member that gives "acidic" polymers; note that all the others carry polar but neutral functional pendants. A polycarboxylic acid similar to $\mathbf{4}$ has been obtained from the vinyl ether of methyl glycolate $\left(6 ; \mathrm{CH}_{2}=\mathrm{CH}-\mathrm{OCH}_{2} \mathrm{COOCH}_{3}\right)$ by its cationic polymerization and subsequent saponification of the product polymer. ${ }^{7}$ The malonate monomer $\mathbf{1}$ is easier to synthesize than 6 and, in view of a wide variety of possible transformation of the malonate function, it would be more versatile as functionalized vinyl ether.

This study focuses on (i) the cationic polymerizability of $\mathbf{1}$ as a vinyl ether with a double ester function, (ii) the possibility of its living cationic polymerization initiated by the $\mathrm{HI} / \mathrm{I}_{2}$ system to produce monodisperse polymers (2) with malonic ester pendants, and (iii) the synthesis of polymeric carboxylic acids 3 and 4 from 2 (eq 1).

\section{EXPERIMENTAL}

\section{Materials}

Vinyl ether 1 was prepared from 2-chloroethyl vinyl ether and malonic ester as reported previously; ${ }^{3,5}$ gas-chromatographic purity $>99.8 \%$; see Figure $3 \mathrm{~A}$ for its ${ }^{1} \mathrm{H}$ NMR spectrum. Anhydrous hydrogen iodide (as an $n$-hexane solution) was obtained by dehydration of commerical hydroiodic acid with phosphorus pentoxide. ${ }^{2}$ Iodine was sublimed over potassium iodide. Boron trifluoride etherate $\left(\mathrm{BF}_{3} \mathrm{OEt}_{2}\right)$ was distilled under re- 
duced pressure. These initiators were sealed in brown ampules under dry nitrogen and stored in a freezer. Toluene (polymerization solvent) and tetrahydronaphthalene (internal standard for gas chromatography) were purified by the usual methods ${ }^{2}$ and distilled over calcium hydride at least twice prior to use.

\section{Polymerization}

Polymerization of 1 was carried out under dry nitrogen in a baked glass tube equipped with a three-way stopcock. The reaction was initiated by adding an initiator solution to a monomer solution via a dry syringe, and was quenched with prechilled ammoniacal methanol; for the $\mathrm{HI} / \mathrm{I}_{2}$-initiated polymerizations, hydrogen iodide and iodine solutions were added sequentially in this order. Conversion of monomer 1 was monitored by gas chromatography with tetrahydronaphthalene $(4.0 \mathrm{vol} \%)$ as an internal standard. The quenched reaction mixtures with $\mathrm{HI} / \mathrm{I}_{2}$ or iodine were washed with $10 \%$ aqueous sodium thiosulfate solution and then with water, evaporated to dryness, and vacuum dried to give the product polymers. The polymerization solutions with $\mathrm{BF}_{3} \mathrm{OEt}_{2}$ were worked up in the same manner except for omitting the treatment with sodium thiosulfate.

\section{Polymer Characterization}

The molecular weight distribution (MWD) of the recovered polymers was measured by size-exclusion chromatography (SEC) in chloroform on a Jasco Trirotar-II chromatograph equipped with three polystyrene gel columns (Shodex A-802, A-803, and A-804). The number-average molecular weight $\left(\bar{M}_{n}\right)$ and polydispersity ratio $\left(\bar{M}_{w} / \bar{M}_{n}\right)$ were obtained from the SEC eluograms on the basis of a polystyrene calibration. ${ }^{1} \mathrm{H}$ and ${ }^{13} \mathrm{C}$ NMR spectra were recorded in $\mathrm{CDCl}_{3}$ or $\mathrm{D}_{2} \mathrm{O}$ at room temperature on a Jeol FX-90Q spectrometer.
Hydrolysis and Decarboxylation of Polymer 2

A sample of polymer 2 ( $\mathrm{ca} .100 \mathrm{mg}$ ) was dissolved in acetone $(18 \mathrm{ml})$, and $2 \mathrm{ml}$ of aqueous sodium hydroxide (5 equiv. to the $\mathrm{COOC}_{2} \mathrm{H}_{5}$ units in the polymer) was added. The turbid mixture was magnetically stirred at room temperature for about $1 \mathrm{~h}$ until a homogeneous transparent solution was obtained. The acetone was then evaporated off under reduced pressure, water $(20 \mathrm{ml})$ was added, and stirring was continued at room temperature for an additional 2 days. The resulting sodium salt of 3 was converted into the free diacid form by treatment with $6 \mathrm{~N}$ hydrochloric acid (equivalent to the sodium hydroxide employed for the saponification). The neutralized solution was concentrated into $c a .5 \mathrm{ml}$ by evaporation and dialized (Spectra/Por 7, molecular weight cutoff $c a$. 1000) for $24 \mathrm{~h}$ to remove the resultant sodium chloride. The purified polymer (3) was isolated by evaporating off the water under reduced pressure.

For decarboxylation, the diacid form 3 was redissolved in water $(20 \mathrm{ml})$, and the solution was heated to $90^{\circ} \mathrm{C}$ for $1 \mathrm{~h}$, followed by evaporating off the water, to give the mono-acid form 4 . Polymers 3 and 4 were characterized by ${ }^{1} \mathrm{H}$ and ${ }^{13} \mathrm{C}$ NMR spectroscopy and conductometric titration.

\section{Conductometric Titration}

The carboxylic acid functions in polymers 3 and 4 were determined by conductometric titration in a glass cell with two platinum electrodes connected to a Wayne Kerr B224 Universal Bridge. In a typical run, a polymer sample $(20-50 \mathrm{mg})$ was dissolved in deionized water $(60 \mathrm{ml}), 0.1 \mathrm{~N}$ hydrochloric acid (ca. $3 \mathrm{ml}$ ) was added, and the solution was titrated with $0.1 \mathrm{~N}$ standard sodium hydroxide solution at room temperature with stirring, while conductance values were read to construct a titration profile by point-mapping. 


\section{RESULTS AND DISCUSSION}

\section{Cationic Polymerization of Vinyl Ether 1}

Malonate monomer 1 was polymerized in toluene at $-40^{\circ} \mathrm{C}$ with $\mathrm{HI} / \mathrm{I}_{2}$, iodine, and $\mathrm{BF}_{3} \mathrm{OEt}_{2}$ as initiators. All of them effectively induced polymerization of 1 . Figure 1 shows the MWD of the polymers thus obtained. $\mathrm{BF}_{3} \mathrm{OEt}_{2}$, as a typical cationic initiator, gave polymers of a fairly high molecular weight $\left(\bar{M}_{w}=6 \times 10^{4}\right)$ and a broad MWD $\left(\bar{M}_{w} / \bar{M}_{n}>\right.$ 2). In contrast, the polymers produced by $\mathrm{HI} / \mathrm{I}_{2}$ and iodine exhibited narrow MWDs; in particular, the $\mathrm{HI} / \mathrm{I}_{2}$ system led to nearly monodisperse polymers with $\bar{M}_{w} / \bar{M}_{n} \leq 1.1$.

These results indicate that the double ester (malonate) pendant does not adversely affect the cationic polymerization of $\mathbf{1}$. The abovedescribed experiments were not optimized with respect to polymer molecular weight, and higher polymers would be obtained at lower temperatures $\left(\right.$ e.g., $\left.-78^{\circ} \mathrm{C}\right)$ and at higher monomer concentrations. The polymerization reactivity of $\mathbf{1}$, relative to other vinyl ethers like 5, is discussed elsewhere. ${ }^{8}$

\section{Living Polymerization of 1 by $\mathrm{HI} / \mathrm{I}_{2}$}

The very narrow MWD of the polymers. obtained with $\mathrm{HI} / \mathrm{I}_{2}$ prompted us to study more in detail the possibility of living cationic polymerization of $\mathbf{1}$. The two diagnostic criteria for the formation of living polymers are an increase in polymer molecular weight $\left(\bar{M}_{n}\right)$ in direct proportion to monomer conversion and a further rise in $\bar{M}_{n}$ on addition of a fresh feed of monomer to a completely polymerized reaction mixture. Figure 2 summarizes the experiments directed toward examining these criteria in the $\mathrm{HI} / \mathrm{I}_{2}$-initiated polymerization of 1 in toluene at $-40^{\circ} \mathrm{C}$.

The first-stage polymerization reached $100 \%$ monomer conversion in ca. $200 \mathrm{~min}$, during which period the $\bar{M}_{n}$ of the product polymers increased proportionally to conversion. When a fresh feed of 1 (equiv. to the first feed) was added to the reaction mixture at the

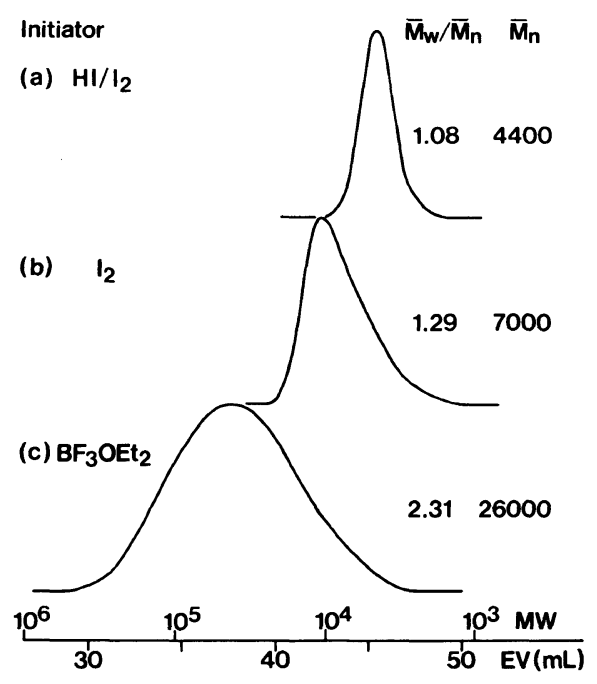

Figure 1. MWD of the polymers obtained in the polymerization of 1 in toluene at $-40^{\circ} \mathrm{C}$ and $[1]_{0}=0.22 \mathrm{M}$ $(5.0 \mathrm{vol} \%)$. Initiator $(\mathrm{mM})$, monomer conversion, and reaction time: (a) $\mathrm{HI} / \mathrm{I}_{2}(12 / 10), 99 \%, 3.4 \mathrm{~h}$; (b) iodine (10), $25 \%, 21 \mathrm{~h}$; (c) $\mathrm{BF}_{3} \mathrm{OEt}_{2}(2.0), 34 \%, 1.5 \mathrm{~h}$.

end of the polymerization, the added monomer was consumed smoothly to give polymers, the $\bar{M}_{n}$ of which continued to increase and was again proportional to monomer conversion. Throughout these experiments, the polymers maintained a very narrow MWD with $\bar{M}_{w} / \bar{M}_{n}$ ranging from 1.1 to 1.2 . Separate runs also showed the polymer molecular weight proportional to the molar feed ratio of the monomer to the initiator (HI). All these data demonstrate the living nature of the polymerization of $\mathbf{1}$ initiated by the $\mathrm{HI} / \mathrm{I}_{2}$ system.

\section{Structure of the Polymers (2)}

Figure 3 (A and B) compares the ${ }^{1} \mathrm{H}$ NMR spectra of monomer 1 and its polymer produced by $\mathrm{HI} / \mathrm{I}_{2}$ in toluene at $-40^{\circ} \mathrm{C}$. Spectrum $\mathrm{B}$ is fully consistent with vinyl ether-type polymer 2 (eq 1), showing no evidence for side reactions and/or decomposition of the pendant malonate group. In Figure 3B, for example, the vinyl resonances of $\mathbf{1}$ (see Figure $3 \mathrm{~A}$, peaks $\mathrm{a}$ and $\mathrm{b}$ ) are absent; the main-chain 


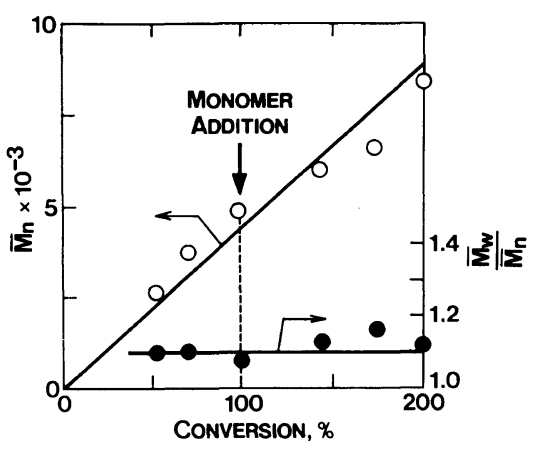

Figure 2. Conversion dependence of the $\bar{M}_{n}$ and $\bar{M}_{w} / \bar{M}_{n}$ values for the polymers obtained in the polymerization of 1 by $\mathrm{HI} / \mathrm{I}_{2}$ in toluene at $-40^{\circ} \mathrm{C}$ before and after the monomer addition: $[1]_{0}=0.22 \mathrm{M}(5.0$ $\mathrm{vol} \%$ ); $[\mathrm{HI}]_{0}=9.4 \mathrm{mM} ;\left[\mathrm{I}_{2}\right]_{0}=9.8 \mathrm{mM}$; the same molar amount of 1 as in the first feed was added to the reaction mixture at $100 \%$ conversion

methylenes now appear as broad peak a; and the ethyl groups of the malonate pendant are seen as peaks $f$ and $g$ in a typical $\mathrm{A}_{2} \mathrm{~B}_{3}$ pattern. Polymer 2 most likely has a methyl head group (h), due to the addition of hydrogen iodide across the vinyl ether double bond of $\mathbf{1}$, and a methoxyl tail group arising from the quenching the living end with methanol. ${ }^{1}$ The head methyl protons (h) are expected to appear as a doublet around at $\delta 1.1$ ( $c f$. spectra C and D, Figure 3, discussed below), ${ }^{1}$ but in spectrum $\mathrm{B}$ the signal apparently overlaps with the strong triplet $\mathrm{g}$.

The formation of $\mathbf{2}$ was also confirmed by ${ }^{13} \mathrm{C}$ NMR spectroscopy: $\delta\left(\mathrm{CDCl}_{3}\right) \quad 168.8$ $(\mathrm{C}=\mathrm{O}), \quad 73.4 \quad$ (main-chain $\mathrm{CH}), \quad 65.3$ $\left(\mathrm{OCH}_{2} \mathrm{CH}_{2}\right), \quad 60.8 \quad\left(\mathrm{COOCH}_{2}\right), \quad 48.6$ (CHCOO), 40.8 and 38.3 (main-chain $\mathrm{CH}_{2}$; racemic and meso, respectively), 29.1 $\left(\mathrm{OCH}_{2} \mathrm{CH}_{2}\right), 13.7\left(\mathrm{CH}_{3}\right)$. The chemical shift value of the ester carbonyl carbons was the same as that for monomer $1 .^{5}$ Integration of the split main-chain methylene signal showed that the steric structure of the sample [isotactic dyad (meso) content $c a .60 \%$ ] is similar to that of poly ( $n$-alkyl vinyl ethers) obtained under the same conditions $\left(\mathrm{HI} / \mathrm{I}_{2}\right.$ or $\mathrm{BF}_{3} \mathrm{OEt} \mathrm{t}_{2}$ initiator, toluene solvent, $\left.-40^{\circ} \mathrm{C}\right){ }^{8,9}$
Synthesis of Polymeric Carboxylic Acids $\mathbf{3}$ and 4

Hydrolysis of Polymer 2. According to the malonic ester synthesis (eq 1$),{ }^{10}$ malonate polymer 2 was hydrolyzed under basic conditions, and subsequent neutralization of the resulting sodium salt led to polymer 3 with free malonic acid pendants. Importantly, the precursor polymer $\mathbf{2}$ was soluble in common organic solvents (toluene, chloroform, etc.) but insoluble in water, whereas the saponification/neutralization products did dissolve in water at room temperature.

NMR Structural Analysis. Figure 3C illustrates the ${ }^{1} \mathrm{H}$ NMR spectrum of the product (H-form) in $\mathrm{D}_{2} \mathrm{O}$ (see Figure 3B for precursor 2). The hydrolysis completely removed the pendant ethyl groups of the precursor (Figure $3 \mathrm{~B}$, peaks $\mathrm{f}$ and $\mathrm{g}$ ); because of this, the head methyl group is now clearly seen as peak $h$. The other signals $(\mathrm{a}-\mathrm{e})$ remained almost unchanged before and after the saponification. The intensity ratio of the broad resonance at $\delta 3-4$ (b, c, and e) to the head methyl signal (h) gave the degree of polymerization of the sample $\left(\overline{\mathrm{DP}}_{n}=24.0\right)$, which was in good agreement with the calculated $\overline{\mathrm{DP}}_{n}$ value for the precursor $(=23.1)$ based on the monomer-toinitiator feed ratio $\left([1]_{0} /[\mathrm{HI}]_{0}\right)$.

The clean and quantitative transformation of 2 into 3 was further shown by ${ }^{13} \mathrm{C}$ NMR analysis of the product. For example, the ethyl carbons of the malonate pendants of the precursor ( $\delta 60.8$ and 13.7) disappeared completely upon hydrolysis. The carbonyl carbons were observed at $\delta 174.6$, shifting from $\delta 168.8$ for 2 , and this chemical shift value indicates that they are now associated with carboxylic acids rather than esters; incidentally, the sodium salt of 3 , isolated before the neutralization, exhibited a carbonyl resonance at $\delta 177.0$.

The malonic acid form 3 was heated in water to $90^{\circ} \mathrm{C}$ for decarboxylation into 4 (eq 1). In the ${ }^{1} \mathrm{H}$ NMR spectrum of the product (Figure 3D), a new absorption ( $\left.\mathrm{e}^{\prime}\right)$ appeared at $\delta 2.4$ 


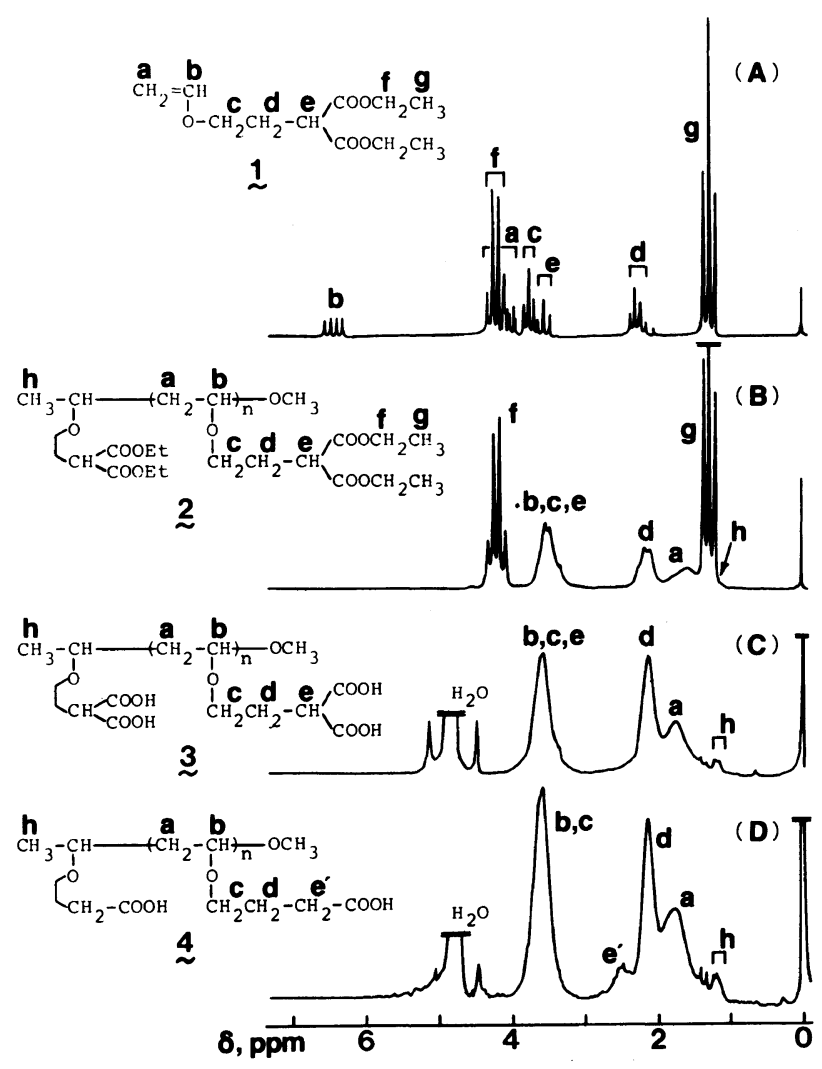

Figure 3. ${ }^{1} \mathrm{H}$ NMR spectra in $\mathrm{CDCl}_{3}$ (A and $\mathrm{B}$ ) and in $\mathrm{D}_{2} \mathrm{O}(\mathrm{C}$ and $\mathrm{D})$ : (A) monomer 1; (B) polymer 2 obtained with $\mathrm{HI} / \mathrm{I}_{2}$ in toluene at $-40^{\circ} \mathrm{C}\left(\overline{\mathrm{DP}}_{n}=23.1 ; \bar{M}_{n}=4900, \bar{M}_{w} / \bar{M}_{n}=1.07\right.$, by SEC $)$; (C) diacid form 3 obtained from sample B: (D) monoacid form 4 obtained from sample C.

2.7, which is assignable to the methylene unit adjacent to a carboxylic acid group. The other peaks $(\mathrm{a}-\mathrm{d})$ were kept unchanged during the decarboxylation ( $c f$. Figure $3 \mathrm{C}$ ). The $\overline{\mathrm{DP}}_{n}$ of the product, based on the signal intensity ratio of $b$ and $c$ to $h$, was 23.5 and very close to the values for 2 (23.1) and 3 (24.0). The ${ }^{13} \mathrm{C}$ NMR spectrum of the decarboxylation products showed a carbonyl resonance at $\delta 174.7$, nearly in the same position as that for the precursor $3(\delta 174.6)$ but one half in signal intensity. These spectral analyses demonstrate the formation of the monoacid form 4 from the diacid counterpart 3.

Conductometric Titration. The structure of 4 was further established by conductometric titration of its carboxylic acid pendants. Figure 4

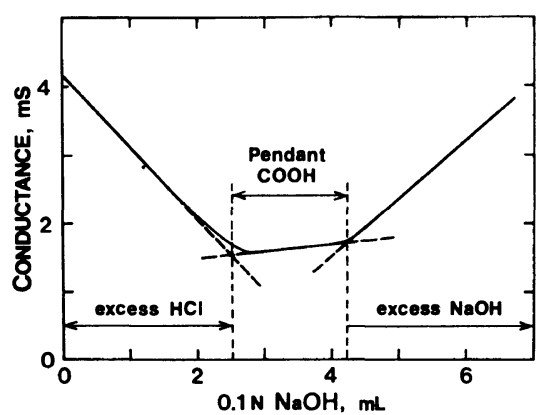

Figure 4. Conductometric titration of polymer 4 (sample D, Figure 3D; $\overline{\mathrm{DP}}_{n}=23.5$ by ${ }^{1} \mathrm{H}$ NMR): 21.2 $\mathrm{mg}$ of $4\left(1.63 \times 10^{-4} \mathrm{~mol}\right.$ of the repeat unit $)$ in $60 \mathrm{ml}$ of deionized water, pretreated with $c a .2 .5 \mathrm{ml}$ of $0.1 \mathrm{~N}$ hydrochloric acid. $\mathrm{COOH}$ content (obsd): $1.66 \times 10^{-4} \mathrm{~mol} ; 1.02 \mathrm{COOH} /$ repeat unit. 
presents a typical example of the titration where a sample of the decarboxylation products was pretreated with excess hydrochloric acid and back-titrated with aqueous sodium hydroxide. The conductance profile exhibited two inflection points, the distance of which corresponds to the amount of the alkali needed to neutralize the pendant carboxylic acids (the weaker acid component in the system). The data gave $1.02 \mathrm{COOH}$ function/repeat unit, again confirming the formation of the monoacid form 4. Separate experiments for the hydrolysis/neutralization product showed its acid content per repeat unit to be about two.

Polymers 3 and 4 are new polyelectrolytes that consist of a monodisperse poly(vinyl ether) backbone and di- and monocarboxylic acid pendants, respectively.

\section{REFERENCES}

1. As recent reviews, see: (a) M. Sawamoto and T. Higashimura, Makromol. Chem., Macromol. Symp., 3, 83 (1986).

(b) T. Higashimura, S. Aoshima, and M. Sawamoto, ibid., 3, 99 (1986).

2. M. Miyamoto, M. Sawamoto, and T. Higashimura, Macromolecules, 17, 265, 2228 (1984).

3. (a) L. H. Cretcher, J. A. Koch, and W. H. Pittenger, J. Am. Chem. Soc., 47, 3083 (1925).

(b) A. Buzas, C. Egnell, and M. Moczar, Bull. Soc. Chim. Fr., 267 (1962).

4. M. Minoda, M. Sawamoto, and T. Higashimura, Polym. Prepr., Jpn., 35, 1324 (1986).

5. M. Sawamoto, T. Enoki, and T. Higashimura, Macromolecules, 20, 1 (1987).

6. S. Aoshima, T. Nakamura, N. Uesugi, M. Sawamoto, and T. Higashimura, Macromolecules, 18, 2097 (1985).

7. D. D. Coffman, G. H. Kalb, and A. B. Ness, J. Org. Chem., 13, 223 (1948).

8. M. Minoda, M. Sawamoto, and T. Higashimura, Polym. Bull., 17, 107 (1987).

9. T. Nakamura, S. Aoshima, and T. Higashimura, Polym. Bull., 14, 515 (1985).

10. See, for example, S. H. Pine, J. B. Hendrickson, D. J. Cram, and G. S. Hammond, "Organic Chemistry," 4th ed, McGraw-Hill, New York, N.Y., 1980, p 423. 